\title{
A GEOQUÍMICA MULTIELEMENTAR NA GESTÃO AMBIENTAL. IDENTIFICAÇÃO E CARACTERIZAÇÃO DE PROVÍNCIAS GEOQUÍMICAS NATURAIS, ALTERAÇÕES ANTRÓPICAS DA PAISAGEM, ÁREAS FAVORÁVEIS À PROSPECÇÃO MINERAL E REGIÕES DE RISCO PARA A SAÚDE NO ESTADO DO PARANÁ, BRASIL
}

OTAVIO AUGUSTOBONI LICHT*

\author{
TESE DE DOUTORADO - Programa de Curso de Pós-Graduação em Geologia - UFPR \\ DATA DE DEFESA: 6 mar. 2001
}

As respostas geoquímicas do ambiente são controladas, em primeiro lugar, pelos processos naturais, geológicos, pedológicos, climáticos e biológicos. Superpondo-se a essa herança, a presença do homem adquire papel importante pelas possibilidades de alteração que promove no ambiente geoquímico a partir das concentrações urbanas, atividades industriais e agrícolas. Na investigação dos relacionamentos geográficos da distribuição de elementos químicos com as feições naturais e as alterações antrópicas, a geoquímica multielementar apresenta-se como um instrumento de grande capacidade de discriminação. A coleta e a análise multielementar da água e dos sedimentos ativos de fundo de bacias hidrográficas de porte médio - $220 \mathrm{~km}^{2}$ - no Paraná, com uma área de $200.000 \mathrm{~km}^{2}$, propiciou a constituição de uma base de dados geoquímicos para o estudo dos padrões de distribuição dos elementos químicos. Outras variáveis numéricas como a densidade populacional e as áreas plantadas com algodão, café, batata e fumo, consideradas como capazes de caracterizar e quantificar o impacto da ocupação humana, foram agregadas à base de dados. Por outro lado, a taxa de óbitos por câncer de fígado (óbitos/100.000 habitantes) foi selecionada para testar a hipótese de ser um indicador capaz de evidenciar o impacto dos resíduos de agrotóxicos nos seres humanos. O mapa das províncias geológicogeomorfológicas, o mapa geológico simplificado, o traçado dos principais lineamentos estruturais e o contorno de anomalias de magnetismo residual foram também utilizados para a identificação de assinaturas geoquímicas características. Pela diversidade de formatos vetoriais de cada tema - polígonos das bacias hidrográficas, limites municipais e mapa geológico, linhas dos lineamentos estruturais e anomalias magnéticas-, a base de dados geoquímicos, geológicos, socioeconômicos e sanitários foi homogeneizada pela aplicação de equações multiquádricas e com a técnica de geoprocessamento de pontoem-polígono. Dessa forma, os teores das variáveis numéricas e os atributos das qualitativas foram homogeneizados e regularizados numa malha composta por pontos espaçados de aproximadamente 5.000 metros. Assim, assinaturas geoquímicas características foram estabelecidas para descrever diversas situações naturais ou antrópicas. Dentre elas, salientam-se as seguintes: as significativas diferenças entre as duas direções principais dos lineamentos, estruturais, com as estruturas de direção NE-SW representadas por uma grande quantidade de elementos, o que reflete os processos de granitogênese, de hidrotermalismo e de mineralização a eles associados; a assinatura geoquímica das águas superficiais associada às anomalias de magnetismo residual da região do Norte Pioneiro, que reforça a hipótese da presença de corpos ou de complexos alcalinos e/ou alcalino-carbonatíticos não aflorantes; o mapa hidrogeoquímico do fluoreto subsidiou a realização de estudos epidemiológicos que identificaram a ocorrência de fluorose dentária grave nos moradores, em idade escolar, da região do Norte Pioneiro; o estabelecimento de um indicador de risco geoquímico para a saúde humana a partir da robusta relação entre os teores de cloretos e brometos nas águas e os municípios com as mais altas taxas de mortalidade por câncer de fígado em seres humanos. Isto poderia indicar o passivo ambiental herdado dos resíduos dos pesticidas clorados e bromados empregados, por muitas décadas, nas culturas de café e algodão do norte do Paraná; o impacto das atividades garimpeiras, - que vem ocorrendo desde 1565 - na região litorânea, é perfeitamente caracterizado pela abundância relativa de mercúrio e de ouro; o impacto de atividades industriais de extração de carvão e seu aproveitamento na geração de termoeletricidade é identificado principalmente pelo sulfato nas águas e pelo cádmio nos sedimentos de fundo, respectivamente. Sob o ponto de vista da indústria mineral, algumas áreas relacionadas com as rochas ígneas básicas da bacia do Paraná demonstraram potencial para a exploração de metais preciosos, principalmente Elementos do Grupo da Platina (EGP) e ouro. Com a aplicação da análise fatorial sobre os dados geoquímicos de águas e sedimentos ativos de drenagem, o território do estado do Paraná foi compartimentado em anomalias regionais e províncias estatística e geoquimicamente homogêneas, refletindo os ambientes naturais e o impacto da ação humana.

*E-mail: otavio@pr.gov.br 